\title{
O cultivo do corpo pela arte marcial chinesa kung fu estilo Choy Lay Fut
}

Body cultivation throughout the Kung Fu Chinese Martial Art Choy Lay Fut style

Débora Zamarioli ${ }^{1}$ 


\section{Resumo}

Neste artigo, reflito sobre a arte marcial chinesa kung fu estilo Choy Lay Fut como um método de cultivo em diálogo com a área de treinamento em atuação. Por esta perspectiva, busco problematizar o complexo enredamento do treinamento em atuação com a amplitude das cosmologias implícitas em diferentes métodos de cultivo e suas implicações no cotidiano do artista cênico-marcial. Para isso, teço reflexões sobre o como os fios da experiência terapêutica com a medicina chinesa transformaram minha percepção sobre os fios cultivados pelo kung fu que, por sua vez, se desenrolaram criativamente no treinamento em atuação.

Palavras-chave: Arte marcial chinesa; cultivo; racionalidade médica; treinamento em atuação

\section{Abstract}

In this article I discuss about the Chinese martial art Kung Fu in its style Choy Lay Fut as a method of self-cultivation in direct dialogue with the performance training area. In this perspective I seek to demonstrate the complex interweaving between the performance training with the extent of the implicit cosmologies in different self-cultivation methods and its implications in the scenic-martial artist daily. In order to that, I debate on how the threads of therapeutic experience with the Chinese medicine have changed my perception over the threads cultivated by Kung Fu which, in turn, have developed creatively in the performance training.

Keywords: Chinese martial art; Self-cultivation; Medical rationale; Performance training
ISSN: 1414.5731

E-ISSN: 2358.6958 
Neste artigo, trago pensamentos investigados na interseção teórico-prática, que tem, na lógica do fazer do corpo, no vento na pele e no choque da luta, guias de questionamentos e procedimentos. Pesquiso a arte marcial chinesa tradicional kung fu estilo Choy Lay Fut como um método de "cultivo" (Quilici, 2015, p.178) em continuidade com a área de treinamento em atuação. Isto significa dizer que o Choy Lay Fut é investigado sob o prisma do seu arcabouço prático-filosófico de treinamento com concepções e qualidades específicas do corpo-mente.

Para desenvolver essa investigação, teço reflexões sobre o como os fios da experiência terapêutica com a medicina chinesa transformaram minha percepção sobre os fios cultivados pelo kung fu que, por sua vez, se desenrolaram criativamente no treinamento em atuação. Em conjunto, esses fios de experiência sugeriram a tessitura de uma espécie de treinamento em rede.

\section{Do corpo em cultivo}

Cassiano Sydow Quilici é um dos mais expressivos pesquisadores das artes cênicas contemporâneas no Brasil. Praticante do Budismo Theravada, Quilici também é diretor, performer e dramaturgo e seu projeto artístico-acadêmico se engaja com a transformação espiritual do homem em suas dimensões políticas, culturais e artísticas. No livro de ensaios $O$ Ator-Performer e as Poéticas da Transformação de Si (Quilici, 2015), Quilici recontextualiza treinamento e técnica à luz de diálogos histórico-culturais a fim de propor um aprofundamento rigoroso e preciso nos métodos de trabalho do ator-performer sobre si.

Para isso, Quilici desenvolve, entre outras abordagens, o conceito japonês shugyō, traduzido como cultivo, em diálogo com a área de treinamento em atuação (Quilici, 2015, p.178). Os métodos de cultivo, articulados inicialmente pelo filósofo japonês Yuasa Yasuo, se referem aos estados transformados da consciência, nos quais se experimenta uma mudança radical na percepção habitual, permitindo ao praticante a experiência budista da "não-mente" ou do "não-eu" (Yuasa, 1993, p.13). Na perspectiva do filósofo, nos métodos de cultivo, o corpo-mente é mais do que uma essência ou algo inato, ele é um estado/sensação de unidade, rigorosamente discriminada através de práticas e preceitos, a ser conquistada através do esforço pessoal, ou seja, de treinamento (Yuasa, 1987, p.98).

Quilici pontua que o cultivo é uma "prática multifacetada que visa florescer certas qualidades humanas latentes" (Quilici, 2011, p.2) com precisas e rigorosas perspectivas e nomeações sobre o homem e das possibilidades da consciência. Em diálogo com o treinamento de atores, o cultivo escaparia do momento de treino ou de ensaio, propondo a transformação da realidade cotidiana de quem o pratica. Dada à complexidade do termo e de suas práticas específicas, tais como as diferentes linhas de yoga, artes marciais e meditação, o pesquisador brasileiro propõe criar na "especificidade das diferenças produzidas" (Quilici, 2011, p.2).

Desta forma, Quilici lança o desafio/ provocação de abordar o treinamento em atuação que se utiliza de métodos de cultivo como "uma cultura do corpo-mente e suas articulações com práticas artísticas" (Quilici, 2011, p.4). Nesse sentido, qual a diferença produzida pela arte marcial chinesa kung fu estilo Choy Lay Fut no treina- 
mento em atuação? Para buscar possibilidades de resposta a essa pergunta, compartilho com o(a) leitor(a) três experiências: terapêutica, marcial e artística.

\title{
Do corpo em experiência terapêutica
}

Essa experiência começa em um processo de cura com a terapêutica chinesa. Antes de iniciar uma sessão, o terapeuta me disse:
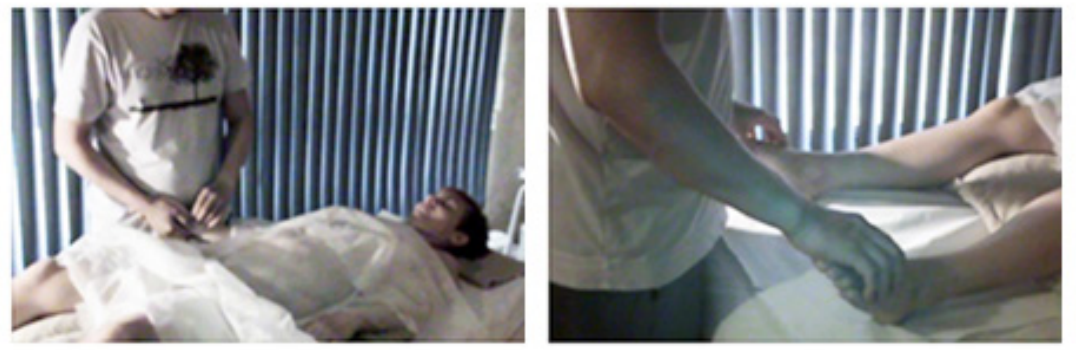

Imagens 1,2 e 3.

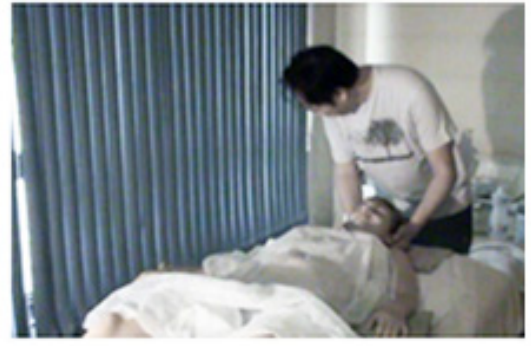

Leitura do pulso. Frames extraídos de vídeo produzido em sessão de acupuntura. Arquivo pessoal da autora.

\begin{abstract}
“- Tem duas coisas. Uma é que a sua menstruação já está plena, então seu pulso é realmente mais cheio. Mas tem uma outra coisa que é uma agitação. Então essa agitação faz você usar a energia mais do que deveria e que te dá a impressão de que você está com pique. Mas não é tão verdadeiro assim o seu pique. Você só está agitada e está usando. Mas não está tão blindada pra sustentar. Então, é falso. Por isso eu te perguntei se você está com fome, porque, normalmente, é típico de que tá enfraquecendo o corpo e o corpo tenda a compensar essa fraqueza trabalhando mais. Então, é como você já estar no final do segundo tempo. Você está cansada, mas sabe que não pode parar porque o jogo continua. Se parar, você pára. Então, você fala, vou apertar até o final do jogo. Então, essa é a sua situação. O pulso do lado esquerdo tá um pouco mais truncado. O pulso do lado direito tá fluindo bem mais. Então, isso mostra que na coluna, alguma parte tá desalinhada. Mas como a gente não pode alinhar porque desceu [referente à menstruação], então a gente faz bastante massagem para soltar. Eu posso até pressionar você um pouquinho para endireitar. Mas, isso quer dizer, você não está alinhada. Tá pinçando o lado esquerdo. [...] O pulso agitado é falso. Você está cansada e tem que descansar. [...] Fora o mental, né? Fora o pensamento muito, muito rápido. Muita coisa, né? Então, vamos harmonizar?" [e inicia a aplicação das agulhas de acupuntura]².
\end{abstract}

Ao posicionar seus dedos em meu punho, tornozelos e cabeça, o terapeuta me advertia sobre a circulação da minha energia interna e sobre as atividades dos meus planos mental, emocional e espiritual. Mas como? Que leitura precisa e sensível era essa apenas a partir da leitura do pulso, da conversa antes de iniciar a sessão e do toque na pele? Que corpo era esse que ele me apresentava?

Pela perspectiva da Racionalidade Médica Chinesa 3 , o corpo é regulado por um sistema de canais, chamados de meridianos, por onde percorre a energia qi. Em resumo, são doze meridianos regulares que conectam mãos, pés e cabeça ao sistema

2 Alex Wong. Sessão de acupuntura registrada em 29/11/2014. Arquivo pessoal da autora.

3 As Racionalidades Médicas (RM) são um projeto desenvolvido no Programa de Pós-graduação em Saúde Coletiva na Universidade Federal Fluminense. O projeto RM propõe a comparação das medicinas homeopática, tradicional chinesa, ayurvédica, antroposófica e ocidental contemporânea (biomedicina). Ela defende que cada racionalidade médica (sistema médico complexo enraizado em sociedades igualmente complexas) é portadora de diferentes conhecimentos. Dentre as dimensões de análise de cada racionalidade médica (morfologia, dinâmica vital, doutrina médica, sistema de diagnose e sistema terapêutico), a cosmologia é a dimensão estruturadora que sustenta cada sistema médico. 
límbico (responsável pela vida emocional e pela memória) e aos órgãos viscerais. Há, ainda, oito meridianos irregulares que funcionam como reservatórios de energia qi. O conjunto desse sistema se difere anatomicamente do sistema nervoso e do sistema circulatório que conhecemos pela biomedicina ocidental e não possui vasos reconhecíveis por essa respectiva anatomia. Entretanto, de acordo com esse conhecimento, a energia qi provê energia para as células do sangue, que são capazes de estocá-la, transportá-la e distribuí-la para todos os sistemas corporais. Essa energia é influenciada pela qualidade do ar inspirado, pelas estações do ano, pela hora do dia, pelo tipo de comida ingerida, pelo estilo de vida, pelas emoções, pelos pensamentos e pela personalidade.

Os conhecidos pontos de acupuntura se situam ao longo desses meridianos que percorrem a superfície do corpo (alguns meridianos também circulam no interior do corpo) e são localizações importantes para identificar mudanças patológicas em algum órgão ou víscera. Nos membros distais, tocados pelo terapeuta, eles são entendidos como poços de energia em comunicação com o mundo externo. E nesse sentido, o corpo na Racionalidade Médica Chinesa é concebido como um sistema de comunicação em rede com o mundo externo. Segundo Marilena do Nascimento, importante referência nas pesquisas sobre o sistema terapêutico chinês, "o corpo é tecido e percorrido pelo qi" (Nascimento, 2006, p.96).

No meu processo de cura com terapêutica chinesa, através de acupuntura, massagem e chi kung, pude sentir a pulsação da energia qi, circulando entre o Céu e a Terra e pelas "Dez Mil Coisas". Na cosmologia chinesa do Tao4, "As Dez Mil Coisas" ou "Os Dez Mil Seres" caracterizam todas as formas e movimentos que existem entre o Céu e a Terra. Doença e saúde são dinâmicas de harmonia e desarmonia do Homem com os Sopros Celestiais e Terrenos e com as Dez Mil Coisas. Por essa perspectiva, o corpo, grosso modo, se configura nas relações de trocas energéticas em rede com o ambiente. Ele é entendido como um processo em constante transformação, no qual há graus de correspondência entre o microcosmo do corpo e o macrocosmo do mundo. O corpo é um conjunto de fios de energia, uma rede de tecido-qi.

Desse processo terapêutico, que durou por volta de seis meses, iniciei um processo de conscientização do cultivo do meu corpo como um universo em fluxo com outros universos: um tecido-qi em troca constante com os Dez Mil Seres. Nesse processo, passei a, por exemplo: proteger meu corpo do vento para que ele não o penetre e desorganize a circulação energética interna ${ }^{5}$; escolher as palavras que serão proferidas ou pensar na necessidade delas para o universo6; preferir alimentos leves e frescos no verão; recolher-me durante o inverno; respeitar os momentos de fraqueza

\footnotetext{
4 Considero importante salientar que a cosmologia chinesa não é um conhecimento simples ou homogêneo. Ela é constituída de conceitos-chave suficientemente abrangentes para ancorar as inter-relações entre cultura, corpo, política e doutrina médica. Para se aprofundar nos aspectos cosmológicos da Medicina Chinesa sugiro a consulta às pesquisas realizadas pelo Grupo "Racionalidades Médicas", em específico: Nascimento. As duas faces da montanha: estudos sobre medicina chinesa e acupuntura. São Paulo: Hucitec, 2006. E, o livro: Wang. Cosmology and Culture. In: Early China. New York: Cambridge University Press, 2000.

$5 \mathrm{Na}$ cosmologia da Racionalidade Médica Chinesa, o vento, por sua qualidade dinâmica e mutável, é capaz de invadir o corpo, causando manifestações patológicas. "Kuriyama Shigehisa (1994) afirma que há poucas coisas no mundo mais perigosas do que o vento na Medicina Chinesa. Ele pode causar dores de cabeça, vômitos, câimbras, tonturas, perda da fala e assim por diante. 'Ferido pelo vento' (shangfeng) um paciente pode queimar em febre e 'derrubado pelo vento' (zhongfeng) pode entrar em coma subitamente. O vento pode causar também loucura e morte"(Greiner, 2013, p.53). Sobre o tratado da patologia do vento, consultar: Chuncai. O Clássico de Medicina do Imperador Amarelo. São Paulo: Roca, 1999, p.90-110.

6 Tal como a cosmologia do Tao, os preceitos Budistas interferem na concepção corporal chinesa, principalmente no que se refere ao comportamento. Na perspectiva Budista para o cotidiano, a fala deve ser vigiada e controlada, a fim de "evitar as quatro transgressões da boca: mentira, duplicidade, palavras ásperas e palavras vãs" (Yün, 2001, p.27).
} 
física; e, não ingerir alimentos de origem animal.

No fluxo de um ano, meu corpo tecido-qi se tornou frio e úmido, no inverno, junto com a terra molhada pela chuva que caiu na ilha de Santa Catarina. Na primavera, o tecido-qi ficou frágil com o vento que veio do Sul, e se encantou com a volta dos primeiros raios de sol que tocaram a varanda. A vida desse tecido-qi entre Céu e Terra foi à imagem da transformação dos elementos yin e yang coagulados nesse ser humano que, chegado ao fim de seus dias, morrerá para tornar-se novamente corpo indiferenciado, outro processo-qi do universo.

A partir dessa experiência, como treinar esse corpo através do kung fu?

\section{Do corpo em treinamento marcial}

Depois de ter passado pela experiência terapêutica e alguns anos de treinamento marcial, passei a me perguntar, como entender o processo de fluxo em rede no corpo do Choy Lay Fut? Ou, ainda, como o corpo é abordado em uma aula de Choy Lay Fut?

As aulas de Choy Lay Fut no Centro de Treinamento Kung Fu Shaolin começam com aquecimento das articulações, alongamentos e treinamento de posturas. $O$ principal objetivo desta primeira parte da aula é preparar a estrutura física, músculos e articulações, para os exercícios seguintes que, geralmente, exigem movimentos mais ágeis e explosivos. Continua-se com sequências de golpes de mãos e posturas de pernas e pés específicas do estilo, que se caracterizam por sua estabilidade, encaixe de quadril e altura baixa.

Depois disso, a rotina das aulas varia, enfatizando diferentes aspectos do treinamento, entre eles: a luta de contato; técnicas de chutes; técnicas de ataque e defesa; condicionamento físico (flexão de braço, abdominais e resistência física); defesas pessoais; e, formas (em cantonês katis ou, em mandarim, taolus), que são golpes encadeados como uma coreografia, realizados individualmente para compreensão e treino de foco, precisão e utilização das técnicas.

A maior parte dos exercícios feitos em aula é realizada sob o comando verbal dos instrutores, que contam (em português ou em cantonês) ou falam os nomes dos golpes. Aprende-se por meio da imitação e da repetição. Cada nova técnica é mostrada pelo professor e os alunos seguem o seu movimento. Depois de memorizado, repete-se diversas vezes com ou sem o comando.

Intercalada ao treino de Choy Lay Fut, no Centro de Treinamento, treina-se técnicas de chi kung: técnicas de respiração aliadas ao movimento e à intenção para trabalhar a energia vital qi. Aprende-se respirações relacionadas aos meridianos do pulmão, fígado, coração, estômago, rim, vesícula e triplo aquecedor. Elas são divididas em respirações yang e yin. Cada uma delas é realizada em momento específico do treinamento, seja para promover mais vitalidade e calor ou para aquietar e esfriar o corpo. Tal como o Choy Lay Fut, o chi kung também é ensinado por meio de imita-

\footnotetext{
7 Em 2007, iniciei o treinamento na arte marcial chinesa tradicional estilo Choy Lay Fut no Centro de Treinamento Kung Fu Shaolin (CTKFS) no bairro da Pompéia, em São Paulo/SP. Esse estilo, introduzido no Brasil em 1992 pelo Mestre Daniel Tomizaki e Mestre Tat Mau Wong, apresenta características de cinco animais: tigre, pantera, garça, serpente e dragão, e combina uma variedade de técnicas de mãos, chutes e armas, tais como bastão, lança, facão, corrente, entre outros. Outras informações sobre a escola e o estilo podem ser acessadas no site: http://www.centrodetreinamentokungfu.com.br/
} 
ção e repetição.

Através dessa breve descrição generalizante de um treino marcial, a priori, o corpo do Choy Lay Fut parece desconectado do corpo de meridianos treinado pelo chi kung. De fato, no começo das minhas experiências, percebia nitidamente o desenvolvimento das habilidades na dimensão física do meu corpo, relacionada aos músculos e às articulações: ganhava força, flexibilidade, coordenação motora, consciência corporal e espacial. Porém, depois de alguns anos, o treinamento começou a extrapolar esses aspectos físicos e passou a solicitar um tipo engajamento mais refinado entre corpo e mente. Percebi que só poderia evoluir no Choy Lay Fut se integrasse a consciência do sistema de meridianos do corpo-rede no treinamento marcial.

Na minha experiência, foi no momento da luta de contato que a necessidade do engajamento em rede entre corpo e mente foi exposta. Por não ter, na minha trajetória, um repertório nem uma memória corporal de contato físico voltado para a luta, estar à frente de um oponente, nesse caso um colega de treino, colocou-me em uma situação de instabilidade mental e emocional ainda não experimentada. Lembro-me que experimentei, em algumas situações de combate (controladas por se tratar de um treino), uma apatia física originada por uma intensa atividade emocional que bloqueava qualquer intuição técnica corporal de ataque ou defesa. Ou seja, muitas vezes, fiquei sem reação: não fugi, não bati, não chutei, não esquivei, mas quis chorar e fiquei com muita raiva de mim mesma por não conseguir lutar. Mas o que torna esse momento tão expressivo?

$\mathrm{Na}$ arte marcial tradicional as técnicas de combate são treinadas para proteger a vida em quaisquer circunstâncias. Em uma situação de luta não desportiva, não há regras quanto à utilização de golpes, isto é, eles podem atingir olhos, garganta, genitais, entre outras áreas vitais. Mas, se o corpo é concebido como uma rede de canais de energia em troca constante com o ambiente, o que significa atingir as áreas vitais? Para além, dos ossos, músculos e articulações, os golpes visam o ataque e defesa dos pontos de manutenção e circulação da energia interna.

Tal qual o vento, que em sua qualidade inerente de imprevisibilidade é capaz de entrar no corpo e transformar as dinâmicas de circulação energética, o oponente também é um fluxo energético em troca. O oponente é imprevisível e coloca o lutador em um estado de atenção ampliado. Neste sentido, o estado de estar em guarda, frente a frente ao oponente, significa colocar o mundo da mente em postura diante de outro mundo, ou ainda, direcionar a mente para o fluxo contínuo de energia com o mundo externo. Nesse momento, corpo e mente devem se entrelaçar em uma mesma rede de emissão e recepção, que por sua vez, se ampliam para a rede do outro e do ambiente: imprevisíveis, inconstantes e impermanentes.

Pela experiência marcial, redimensionada pelos paradigmas terapêuticos, seria o objetivo de cultivo do treino marcial, transformar a relação entre meu corpo e mente em uma única e flexível rede com o outro? Se sim, por esse caminho, como investigar procedimentos de treinamento em atuação na interface com meridianos e pontos de energia? 


\title{
Do corpo em experiência de treinamento em atuação
}

Como a concepção corporal de fluxo do método de cultivo proposto se corporifica em situação de treinamento em atuação?

No artigo Asian Martial Arts as a "Way" for Actors, de Richard Nichols (Zarrilli, 1993, p.19-30), há uma lista de benefícios resultantes do treinamento de artes marciais asiáticas no treinamento em atuação:

\author{
Desenvolvimento do foco (concentração). \\ Estar no momento presente; "no aqui e agora". \\ Localização de imagens. \\ Foco e economia de energia na ação/ gestos. \\ Realizar uma ação por vez. \\ Expansão da auto-imagem. \\ Desenvolvimento da flexibilidade, do controle e do equilíbrio do corpo. Unifica- \\ ção mente e corpo. \\ Apreciação e desenvolvimento da disciplina (Nichols apud Zarrilli, 1993, p.20). \\ (Tradução nossa) ${ }^{8}$
}

Quando essa lista foi elaborada, a adaptação das artes marciais asiáticas para o treinamento de atores é percebido por Nichols como o desenvolvimento de um bom caminho ao ator em formação, inerente a qualquer arte marcial. Ao consultar os principais autores brasileiros e estrangeiros sobre o tema (Barba; Savarese, 1995; Miranda, 2010; Mroz, 2011; Zarrilli, 1993, 2009), verifiquei que, em última instância, a maior parte dos artistas-autores apresenta em seus discursos a preocupação com o treinamento das artes marciais asiáticas como técnica para aumentar as habilidades de representação dos atores (seja na construção de personagens, na execução de ações estilizadas ou não realistas ou em uma desejável velocidade de resposta a estímulos internos ou externos ao atuante) e/ou aumentar sua qualidade de presença cênica através de uma conexão específica entre corpo e mente, conjugando conhecimentos da medicina ocidental com conceitos de energia qi, tan tien e yin/yang.

Como resume aritmeticamente o pesquisador e um dos pioneiros dessa área no Brasil, Cesário Alencar, da Universidade Federal do Pará, "quando praticadas para o fim da 'agência', 'vigor', 'pré-expressividade' e 'presença', as Artes Marciais equacionam uma simples aritmética: rotina + disciplina = controle psicofísico" (Alencar, 2006, p.2).

Todavia, depois de iniciar minha jornada no treinamento da arte marcial chinesa Choy Lay Fut complementado pela vivência na terapêutica chinesa, fui impelida a desviar o olhar do controle psicofísico mais geral e mergulhar na especificidade desse método cultivo. Na esteira de pensamento proposta por Quilici - de articular as práticas artísticas à cultura do corpo-mente dos métodos de cultivo - o treinamento passou a ser um modo de existência no qual as esferas do cotidiano e da arte se fundem em uma mesma rede.

Foi em uma improvisação na Lagoa do Peri, uma reserva ambiental em Florianópolis, que despertei para a união entre arte, cotidiano e arte marcial.

8 Development of focus (concentration). Staying in the moment; "the here and now". Placement of images. Focus of energy and economy in action/gesture. Playing one action at time. Expanding the horizons of self-image. Development of flexible, controlled and balanced body. Unification of mind and body. Appreciation and development of discipline (Nichols apud Zarrilli, 1993, p.20). 

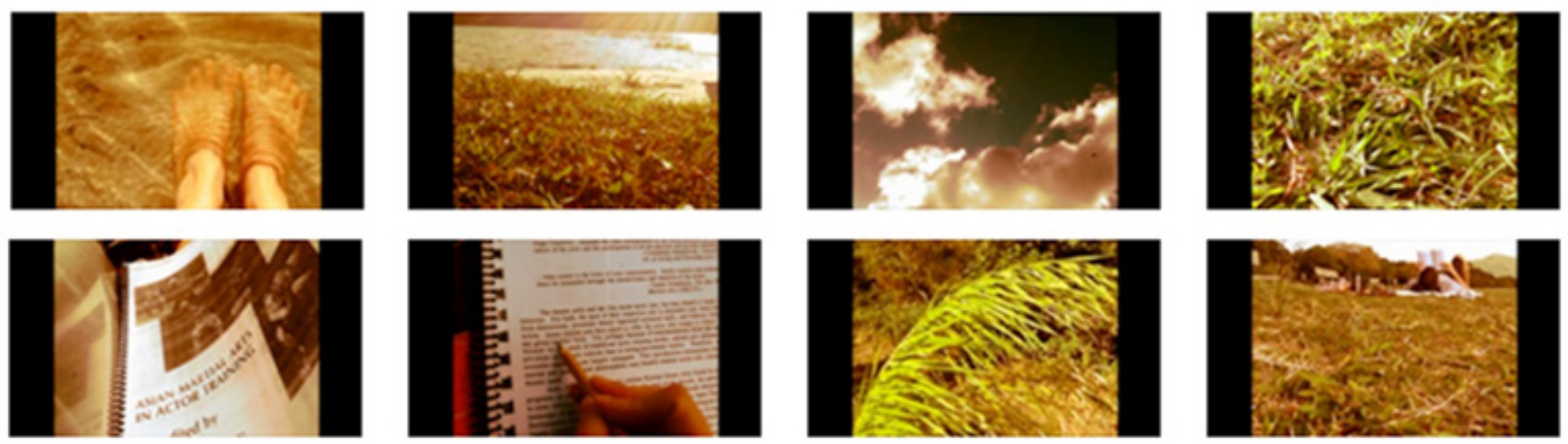

Imagens 4, 5, 6, 7, 8, 9, 10 e11.

Frames extraídos de vídeo produzido na Lagoa do Peri. Arquivo pessoal da autora.

Acompanhada do meu companheiro que iria fazer o registro, me posicionei na areia na beira da água de olhos fechados para improvisar. Não sabia por onde começar, tampouco sabia o motivo de estar ali. Apenas aceitei o convite do próprio espaço e quis traduzi-lo em movimento.

A água, o vento e o sol direcionaram a minha atenção à pele. Minha pele foi a minha primeira interface de criação de movimento. Entretanto, em curtos intervalos de tempo, muitos pensamentos me arrastavam às palavras escritas lidas em algum momento, aos princípios técnicos do "bom ator" aprendidos ao longo dos anos de formação, à lista de Nichols, às autocríticas do que é ou não confortável e corriqueiro na minha movimentação. Como improvisar com tanto julgamento?

Lembro-me de que uma das estratégias para parar esse ciclo de julgamentos foi o princípio da meditação de não apego ao pensamento, aprendido nos treinos marciais. Deixar o pensamento passar, sem segui-lo ou desenvolvê-lo. Apoiei-me, então, nas sensações. Assim, sensível ao vento, a pele se manifestou em movimentos curvilíneos e lentos. Mostrou pequenos tremores sob a influência da água, causando ondas através da coluna. Ativou-se pelo contato com o ambiente na sola dos pés, nas palmas das mãos e no rosto. Claro que isso diminuiu a sensação de divisão da mente, porém ainda sentia-me confusa com os estímulos externos e internos.

Havia a qualidade de desordem interna quando se chocavam sequências de lógicas teóricas e as sensações que tocavam a pele. Desejei a beleza da natureza em mim e senti as limitações do meu corpo físico, trazendo uma recorrente sensação de monótona criatividade. Almejei a simplicidade e me deparei, a todo o momento, com a complexidade do ego.
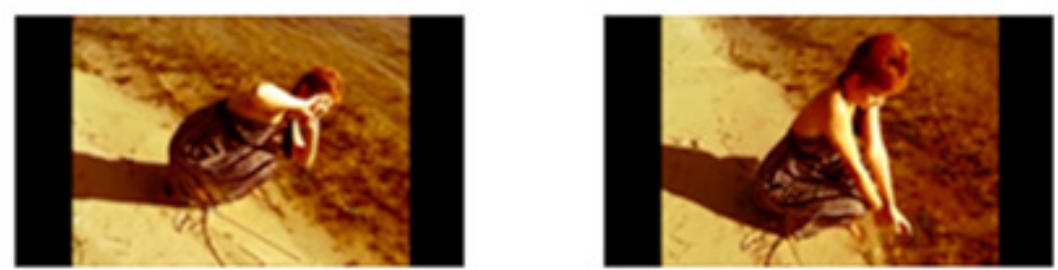

Imagens 12, 13 e 14.

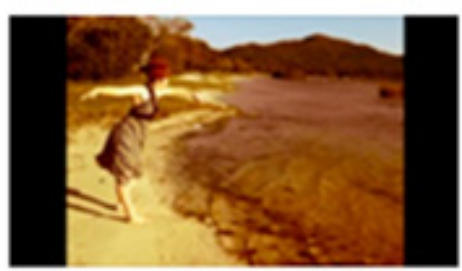

Frames extraídos de vídeo produzido na Lagoa de Peri. Arquivo pessoal da autora.

$E$, com tudo isso, me perguntava onde estava o kung fu e o corpo da Racionalidade Médica Chinesa? São apenas formas e qualidades de movimentos? São ferra- 
mentas e princípios para qualquer improvisação? São metáforas?

Uma pista para possíveis respostas veio sem o meu controle: depois de ir embora notei uma pequena mancha avermelhada no meu tornozelo que no dia posterior iria se manifestar como uma real picada de inseto que inchou e coçou muito! Coincidência? Sim ou não, ela me fez refletir sobre os atravessamentos sofridos pelo e no corpo e o constante diálogo entre corpo e ambiente. Essa pequena (grande) picada imprimiu na minha pele sensações posteriores à experiência presencial na Lagoa. Era como se a Lagoa continuasse em mim, como se um ser burlasse a hierarquia de seleção da minha mente e impusesse o seu diálogo. Afinal, eu estava em troca com o ambiente, não?

Dessa experiência, a pele ficou marcada. E não foi apenas o sinal deixado provavelmente por uma formiga, mas, também, a impressão do vento, do calor, da água e das diferentes texturas tocadas. A pele se manifestou e foi manifestada como lugar de passagem, estampada pelos acontecimentos vividos. O corpo se sentiu pele, calor, medo, confusão, água, formiga, palavras, teorias, memórias, vaidades e bênçãos. A pele se continuou no pôr do sol, na calmaria da lagoa e no veneno do inseto. Teria a picada do inseto a eficácia de uma agulha de acupuntura? Desse encontro, ativaram-se fios da pele que se estenderam pelo interno do corpo, entrelaçando órgãos, fluídos, gases e sólidos. Assim, cada camada de pele, de membrana e de fronteira foi enredada pela vibração do momento daquela realidade.

Aflorou-se o sentido de continuidade entre consciência e inconsciência, entre pele e ambiente, onde os encontros são processos de transformação imersos no universo. Corporifiquei a atenção para o fluxo do tecido-qi que está sempre a se atualizar constantemente, independente ou não da vontade do eu, gerando e transformando fios de fluxos invisíveis com as Dez Mil Coisas. Nesse sentido, os fluxos existem por si mesmos, em constantes mutações, imersos na realidade e sem razão fora do mundo.

Teria meu treinamento em atuação acontecido naquela picada de inseto? Em um encontro banal, pequeno e indesejado? Apesar dos meus esforços em tornar importante e poético meu treinamento artístico-marcial, foi uma formiga que me fez despertar para o inesperado do encontro em rede.

\section{Do corpo em rede}

Em fluxo, o corpo se nutriu em movimento, se nasceu e se pôs todos os dias, se esfriou e se esquentou, se sentiu e se morreu.

$\mathrm{Na}$ delicadeza dos fios tecidos pelo sutil, o corpo se fez em imperceptíveis encontros em rede.

Dessa forma, o corpo pensou e sentiu o tempo, o espaço e as Dez Mil Coisas.

Foi na cura, na dança e na luta, que o corpo se sentiu ancestral e amigo das Dez Mil Coisas.

Picado por agulhas, o corpo percebeu as limitações dessa dimensão e vislumbrou a presença de outros universos. Almejou a libertação, se apegou à vida, quis o Tao, o Meio e a Sabedoria.

Massagens rasgaram o corpo e as mãos acolheram os órgãos. Fez-se quente e macio como a escuta de uma canção de ninar. 
Pela experiência vivida, o corpo se transformou em formiga, em vento, em grama, em nuvem, em Nichols, em qi e em filosofia, em Choy Lay Fut, em frustração e dor, em água, em marcas, em fantasmas...

Da cabeça e do ventre, o corpo se transformou em coração/mente, em portas, janelas e frestas para os animais do Choy Lay Fut: serpente, garça, pantera, tigre e dragão.

Dos animais, o corpo imitou o gesto, o fluxo vital, a compaixão e parou de comê -los.

Das lesões e das dores físicas, o corpo se ressentiu, se amedrontou e custa a se pensar forte e indestrutível. Encoraja-se e se esquiva.

Das emoções, o corpo pensa no amor e em seus demônios e se aquieta.

Em um dia frio, o corpo chorou, comeu pimenta vermelha e sorriu.

Na rede de cura, dança e luta, o corpo se curou dançando, se dançou lutando, se lutou curando, se curou lutando, se dançou curando, se lutou dançando.

Seria as experiências das corporificações dessa rede, a diferença produzida pela especificidade do Choy Lay Fut? Se por um lado, a resposta parece apontar para uma afirmativa devido à concepção do corpo em rede da Racionalidade Médica Chinesa, por outro lado, o caminho não é único. Sem a pretensão de esgotar as possibilidades de experiência do corpo no treinamento em atuação com as artes marciais chinesas ou reduzi-la a um único estilo, esse artigo pretendeu esboçar vias de compreensão e de aproximação pela especificidade.

Abordar a arte marcial chinesa, no caso desse artigo o estilo Choy Lay Fut, como um método de cultivo moveu meu interesse para a investigação de sua concepção corporal nas dimensões terapêuticas, marciais e artísticas. Ainda sob muitas generalizações, a rede tecida por esses fios necessita de investigações mais profundas e cada vez mais apoiadas na diferença guiada pelo próprio estilo marcial. Todavia, a provocação feita pela perspectiva do cultivo problematiza o complexo enredamento do treinamento em atuação com a amplitude das cosmologias implícitas nos diferentes estilos de arte marcial e suas implicações no cotidiano do artista cênico-marcial.

\section{Referências}

ALENCAR, Cesário Augusto P. de. Artes Marciais no Treinamento do Ator. Teatro Caleidoscópio [online], p. 1-5, 2006.

BARBA, Eugenio; SAVARESE, Nicolas. A Arte Secreta do Ator: Dicionário de Antropologia Teatral. Campinas: Hucitec e Universidade de Campinas, 1995.

CHUNCAI, Zhou. Clássico de Medicina do Imperador Amarelo: tratado sobre a saúde e vida longa. São Paulo: Rocca, 1999.

GREINER, Christine. O Corpo e a Cognição nas Artes do Japão. Colóquio Movimentos Interdisciplinares: Corpo, Gesto e Cogniçao, v. 3, n. 6, p. 50-61, 2013. 
MIRANDA, Maria Brígida de. Playful Training: towards capoeira in the physical training of actors. Saarbrücken: Lambert Academic Publishing, 2010.

MROZ, Daniel. The Dancing Word: an embodied approach to the preparation of performers and the composition of performances. Amsterdam - New York: Editions Rodopi B. V., 2011.

NASCIMENTO, Marilene Cabral do. As Duas Faces da Montanha: estudos sobre medicina chinesa e acupuntura. São Paulo: Hucitec, 2006.

QUILICl, Cassiano Sydow. O Conceito de "Cultivo de Si " e os Processos de Formação e Criação do Ator / Performer. VI Reunião Científica da ABRACE - Porto Alegre, p. 5, 2011.

O Ator-Performer e as Poéticas da Transformação de

Si. São Paulo: Annablume, 2015.

WANG, Aihe. Cosmology and Political Culture in Early China. New York: Cambridge University Press, 2000.

YUASA, Yasuo. The Body: toward an Eastern mind-body theory. Albany: State University of New York Press, 1987.

The body, self-cultivation, and ki-energy. New York: State University of New York Press, 1993.

YÜN, Hsing. Cultivando o Bem: uma perspectiva budista para o cotidiano. São Paulo: Cultura Editores Associados, 2001.

ZARRILLI, Phillip. Asian Martial Arts in Actor Training. Madison: University of Wisconsin-Madison, 1993.

Psychophysical Acting: An Intercultural Approach after Stanislavski. New York: Routledge, 2009. 